\title{
INFLUENCE OF PHYSICAL TRAINING ON THE FUNCTION OF AUTONOMIC NERVOUS SYSTEM IN PROFESSIONAL SWIMMERS
}

\author{
Klaudia Palak $^{1(\mathrm{~A}-\mathrm{F})}$, Agata Furgała ${ }^{2(\mathrm{~A}-\mathrm{F})}$, Piotr Biel ${ }^{1(\mathrm{~B})}$, Zbigniew Szyguła $^{3,4(\mathrm{~A}, \mathrm{D}, \mathrm{E}, \mathrm{F})}$, Piotr J. Thor $^{2(\mathrm{~A}, \mathrm{D}, \mathrm{E}, \mathrm{F})}$ \\ ${ }^{1}$ Study Center for Physical Education and Sport, AGH University of Science and Technology in Cracow, Poland \\ ${ }^{2}$ Department of Pathophysiology, Jagiellonian University Medical College in Cracow, Poland \\ ${ }^{3}$ Department of Sports Medicine and Human Nutrition, University School of Physical Education in Cracow, Poland \\ ${ }^{4}$ Academy of Social Sciences, Łódź, Poland
}

\begin{abstract}
Introduction: Regular endurance - type physical exercise exerts positive effect on the capacity and endurance of body and the activity of the autonomic nervous system (ANS). In contrast, the exercise load used in professional sport may lead to significant functional impairment of all tissues and organs, including ANS. These changes can lead to overtraining phenomenon.

Objective: To analyze the influence of prolonged - intense, single - moderate, and single - intense physical exercise on the function of ANS in the training group of swimmers.

Methods: The study included 10 healthy swimmers and 31 healthy volunteers as the control group. The activity of ANS was evaluated on the basis of the temporal and frequency indices of heart rate variability (HRV): mRR, SDNN, pNN50, rMSSD, TP, LF, HF, and LF/HF. The measurements were taken twice: during the preparatory (January 2012) and competition (May 2012) phases of the yearly training cycle, prior to and after the training.

Results: Compared to respective pre-training values, a significant decrease in HRV indices: $\operatorname{SDNN}(P<0.015)$ and pNN50 $(P<0.047)$, was documented after the training session conducted during the preparatory phase. In contrast, a decrease in mRR $(P<0.013)$ and pNN50 $(P<0.028)$ was observed during the competition phase. We did not observe significant differences in values of frequency HRV indices determined during the preparatory phase and following four months of training, i.e. during the competition phase.

Conclusions: No significant changes in various vegetative indices in response to an applied load of swimmers. This suggests that such a high training load is safe and is not associated with the signs of overtraining.
\end{abstract}

Key words: autonomic nervous system, physical exercise, heart rate variability, swimmers

\section{Introduction}

Moderate and regular endurance-type physical exercise is widely believed to exert positive effect on the capacity and endurance of body and the activity of the autonomic nervous system (ANS). Standard response of ANS to moderate physical exercise includes a decrease in vagal tone, i.e. the parasympathetic component, followed by an increase in the sympathetic component. Discontinuation of the exercise is reflected by the rapid restoration of the parasympathetic function at stable baseline equilibrium. The presence of such autonomic reaction was observed in response to a single bout of exercise and during many months of exercise load $[1,2,3,4]$.

Due to its duration and intensity, the exercise load in professional sport is so heavy that it may lead to significant functional impairment of all tissues and organs, and particularly ANS [5]. Extremely intense and prolonged training loads applied during preparatory period to competition was revealed to be reflected by an unfavorable persistent switch in vegetative activity from parasympathetic predominance to sympathetic predominance. This phenomenon is observed in the course of so-called overtraining syndrome, which is quite often observed in professional athletes, but still relatively frequently ignored by their coaches. Among other symptoms, this syndrome manifests by the loss of form and depressive mental changes, which is reflected by achieving poorer results during a competition $[6,7,8]$. It is necessary to control infections that due to congestion are common in athletes. There are interesting studies that show the changes occurring in the values of HRV variables and the risk of infections in swimmers [9].

The aim of each athlete is to reach the level of body adaptation to discipline-specific exercise enabling him/her to achieve optimal results. This objective can be met by proper planning and execution of trainings, with the effectiveness of the latter being determined by the volume, intensity, and periodization of training stimulation [10] as well as by the psychological profile of the athlete $[8,11,12]$. 
Professional athletes, achieving master class results, are comprehensively monitored during their training process. The analysis includes the volume and structure of training load; also the functional body capacity is controlled on an ongoing basis. This reduces the risk of unfavorable fatigue or overtraining that would impair the process of preparation for competition. However, as most previously published papers dealing with the problem in question included master class athletes [13], the number of studies involving sportspersons characterized by lower achievements is relatively sparse.

The number of athletes whose sports level is lower than master class is higher which hinders their comprehensive observation. Usually, such athletes are subjected to standard medical examination twice a year, and the physiological and medical control of their training effects is limited. Consequently, the evaluation of the real status of their body systems at various stages of yearly training cycle, including the examination of ANS and cardiovascular system, is incomplete.

The aim of this study was to analyze the influence of variably long (prolonged intense, single moderate, and single intense) physical exercise on the function of ANS in the training group of swimmers.

\section{Methods}

The study included athletes from the swimming section of the University Sports Association Club at the AGH University of Science and Technology in Cracow. Ten professional swimmers were enrolled (experimental group), among them 5 women and 5 men, with the mean age amounting to $21 \pm 2$ years (range 19-23) and training experience equal to $10 \pm 3$ years. The group of swimmers included one with an International Master Class, one with a Master Class, and four with each of the First and Second Sports Classes.

The control group comprised individuals who neither currently nor previously practiced any sports discipline. These individuals were characterized by a moderate level of physical activity and participated in 60-minute sessions of physical activity twice a week on average, either as a part of physical education classes included in their study curriculum or on their own. Thirty-one controls were examined, including 9 women and 22 men, mean age $20 \pm 1$ years (range 19-21 years).

The inclusion criteria of the study included negative history of cardiovascular disorders, diabetes, neurological disorders, using medications influencing the activity of ANS, other medications, and such stimulants as coffee, cigarettes, and caffeine-containing drinks. All participants had normal arterial blood pressure and heart rate and showed normal sinus rhythm on ECG.

\section{Protocol of the study}

The training schedule aimed at the preparation to competition included the following consecutive phases which differed with regards to their volume, intensity, and duration.

The first stage of the study was conducted during the phase of transitory training (January 2012) and corresponded to the maintenance training after the $1^{\text {st }}$ training macro-cycle. The transitory phase was characterized by the maintenance of functional level achieved during the 1st training macro-cycle of the $2011 / 2012$ season. The aims of this phase included the maintenance of general and comprehensive preparation (aerobic endurance, application of threshold-level tasks and speed components) at a proper level.

The second stage of the study took place during the phase of competition training (May 2012) immediately prior to the main event of the season (Senior and Youth National Polish Championships). The competition phase was characterized by training of lower volume but higher intensity, progressively increasing to its maximal level (aerobe-anaerobe exercise, threshold components at the level corresponding to VO2max, and speed tasks).

The number of training units per week of transitory and competition phase was the same.

The protocol of the study was approved by the Local Bioethical Committee of the Jagiellonian University (approval no. KBET/26/B/2012). All qualified individuals gave their informed written consent to participate in the study.

\section{Evaluation of the autonomic nervous system}

The indices of HRV in the experimental group were determined four times: prior to and after the training at the end of the preparatory and competition phases of the yearly training cycle. In contrast, the HRV of the control group was determined only once.

The examination took place at conditions promoting the comfort of the subjects: at a massage room, during the morning hours, and at least 12 hours after the last training session. All the evaluations were made by the same examiner. The subjects consumed their last meal (light breakfast) at least two hours prior to the examination. A 10-minute electrocardiographic recording at rest was obtained from each subject, with a single measurement of arterial blood pressure. The examination was preceded by a 20 -minute rest in a supine position, in order to stabilize the function of cardiovascular system and ANS activity. Resting electrocardiograms were recorded with a threechannel digital recorder AsPEKT 700, which registers electrocardiographic signaling without compression on PCMCIA semiconductor memory cards. The measurements of arterial pressure were obtained with HOMEDICS MiBody 360 sphygmomanometer. 
Prior to HRV analysis, the fragments containing $\mathrm{R}-\mathrm{R}$ intervals determined by sinus stimulation were selected. The R-R intervals representing the extrasinus stimulation were excluded, as well as the artifacts that were mistakenly identified as stimulation by the analyzer. The preparation of recording for further examination included its automated analysis, edition of its results by a physician with the identification of sinus, supraventricular, ventricular stimulations and artifacts, exclusion of stimulations other than sinus stimulation, verification of extreme values of $R-R$ intervals and extreme differences between consecutive R-R intervals during the sinus rhythm. After the preparation of electrocardiograms, the variability of sinus rhythm was evaluated by means of temporal and spectral analysis at proper, predefined time periods. The analysis was conducted with HolCARD 24W software, version 5.11.00 (Aspel, Poland).

The following components of the time domain analysis of HRV were determined: $\mathrm{mRR}$ - average R-R interval of the sinus rhythm, SDNN - standard deviation of the average R-R intervals of the sinus rhythm (in ms); a global index which describes the total variability of sinus rhythm; rMSSD - square root of the mean squared difference of successive R-R intervals (in $\mathrm{ms}$ ); a measure which refers to the short-term variability, and correlates with the high-frequency component of spectral analysis; pNN50 - proportion of successive R-R intervals that differ by more than $50 \mathrm{~ms}$, expressed in \%, which correlates significantly with rMSSD. Also the measures determined during the spectral analysis were studied: TP (Total Power), total spectral power at the whole range of frequencies (0.0033-0.15 Hz); LF (Low Frequency), low-frequency component $(0.04-0.15 \mathrm{~Hz})$, modulated by the sympathetic system, associated with the cyclic changes of arterial blood pressure, and dependent upon baroreceptor activity; HF (High Frequency), high-frequency component $(0.15-0.4 \mathrm{~Hz})$, variability modulated by the parasympathetic system, associated with breathing; LF/HF, low-frequency to high-frequency component ratio, defines mutual relationships of the components of vegetative modulation; and normalized values of the HRV spectral indices: NLF- normalized low frequency power and NHF- normalized high frequency power, calculated from the form: $\mathrm{NLF}=\left[\left(100^{*} \mathrm{LF}\right) /(\mathrm{TP}-\mathrm{VLF})\right]$ or $\mathrm{NLF}=[\mathrm{LF} /(\mathrm{TP}-\mathrm{VLF})]^{\star} 100, \mathrm{NHF}=\left[\left(100^{\star} \mathrm{HF}\right) /(\mathrm{TP}-\right.$ $\mathrm{VLF})]$ or $\mathrm{NHF}=[\mathrm{HF} /(\mathrm{TP}-\mathrm{VLF})]^{\star} 100[14]$.

\section{Statistical analysis}

Database management and statistical analyses were performed using the SPSS v.17 software. The results were presented as mean values and their standard deviations. Non-normality of data was demonstrated by Shapiro-Wilk's test. Non-parametric tests for small samples were used. Comparisons between investigated groups for quantitative variables were calculated by using Wilcoxon signed rank test if either distribution compared was not normal. Statistical analyses of the influence of exercise (training) were performed using Mann-Whitney- $U$ test. The level of statistical significance was set at $P<0.05$.

\section{Results}

\section{Influence of long-term intense physical exercise on the activity of ANS in swimmers}

Following four months of preparatory training, we did not observe significant changes of indices registered in our group of swimmers (Table 1). Moreover, no signs of excessive parasympathetic tension were documented in response to such intense and long-term training load. There was an insignificant decrease in the values of all HRV indices but $\mathrm{mRR}$ and $\mathrm{LF} / \mathrm{HF}$ ratio, suggesting an increase in the activity of sympathetic component and/or a decrease in the activity of the parasympathetic component.

Table 1. Comparison of mean indices of temporal and spectral HRV analysis determined at rest in the group of swimmers $(n=10)$ during the preparatory and competition phase of a training cycle

\begin{tabular}{cccccc}
\hline \multirow{2}{*}{ Index } & \multicolumn{2}{c}{ Training during the preparatory phase } & \multicolumn{2}{c}{ Training during the competition } \\
phase & $P$ \\
\cline { 2 - 5 } & mean & SD & mean & SD & 0.508 \\
\hline mRR [ms] & 909.20 & 98.41 & 915.70 & 91.38 & 0.284 \\
SDNN [ms] & 158.90 & 79.67 & 128.00 & 45.01 & 0.445 \\
pNN50 [\%] & 33.35 & 14.85 & 28.91 & 17.22 & 0.169 \\
rMSSD [ms] & 82.10 & 42.91 & 72.70 & 51.35 & 0.139 \\
TP [ms $\left.{ }^{2}\right]$ & 2551.90 & 917.57 & 2224.70 & 845.12 & 0.386 \\
LF [ms $\left.{ }^{2}\right]$ & 756.20 & 258.28 & 699.50 & 233.95 & 0.169 \\
HF [ms $\left.{ }^{2}\right]$ & 802.40 & 447.75 & 696.50 & 426.24 & 0.28 \\
LF/HF & 1.03 & 0.22 & 1.13 & & 0.285 \\
\hline
\end{tabular}


Table 2. Comparison of mean indices of temporal and spectral HRV analysis determined at rest prior to and after the training in the group of swimmers $(n=10)$ during the preparatory phase of a training cycle

\begin{tabular}{|c|c|c|c|c|c|}
\hline \multirow[t]{2}{*}{ Index } & \multicolumn{2}{|c|}{$\begin{array}{l}\text { Training during the preparatory phase } \\
\text { - measurement prior to the training }\end{array}$} & \multicolumn{2}{|c|}{$\begin{array}{l}\text { Training during the preparatory phase } \\
\text { - measurement after the training }\end{array}$} & \multirow[t]{2}{*}{$P$} \\
\hline & mean & $\mathrm{SD}$ & mean & SD & \\
\hline $\mathrm{mRR}$ & 909.20 & 98.41 & 818.20 & 92.15 & 0.059 \\
\hline $\mathrm{SDNN}[\mathrm{ms}]$ & 158.90 & 79.67 & 99.00 & 36.26 & 0.015 \\
\hline pNN50 [\%] & 33.35 & 14.85 & 21.07 & 14.79 & 0.047 \\
\hline $\mathrm{rMSSD}[\mathrm{ms}]$ & 82.10 & 42.91 & 57.90 & 25.82 & 0.185 \\
\hline $\mathrm{TP}\left[\mathrm{ms}^{2}\right]$ & 2551.90 & 917.57 & 1994.80 & 695.61 & 0.203 \\
\hline $\mathrm{LF}\left[\mathrm{ms}^{2}\right]$ & 756.20 & 258.28 & 596.30 & 172.70 & 0.241 \\
\hline $\mathrm{HF}\left[\mathrm{ms}^{2}\right]$ & 802.40 & 447.75 & 658.40 & 302.72 & 0.799 \\
\hline $\mathrm{LF} / \mathrm{HF}$ & 1.03 & 0.22 & 1.01 & 0.32 & 0.575 \\
\hline
\end{tabular}

Table 3. Comparison of mean indices of temporal and spectral HRV analysis determined at rest prior to and after the training in the group of swimmers $(n=10)$ during the competition phase of a training cycle

\begin{tabular}{cccccc}
\hline & \multicolumn{2}{c}{$\begin{array}{c}\text { Training during the competition } \\
\text { phase - measurement prior to the } \\
\text { Index }\end{array}$} & training & $\begin{array}{c}\text { Training during the competition pha- } \\
\text { se - measurement after the training }\end{array}$ & $P$ \\
\cline { 2 - 4 } & mean & SD & mean & SD & 0.013 \\
mRR & 915.70 & 91.38 & 826.50 & 83.70 & 0.169 \\
SDNN [ms] & 128.00 & 45.01 & 113.10 & 66.14 & 0.028 \\
pNN50 [\%] & 28.91 & 17.22 & 20.85 & 14.64 & 0.241 \\
rMSSD [ms] & 72.70 & 51.35 & 61.60 & 38.44 & 0.114 \\
TP [ms $\left.{ }^{2}\right]$ & 2224.70 & 845.12 & 1993.50 & 936.76 & 0.114 \\
LF [ms $\left.{ }^{2}\right]$ & 699.50 & 233.95 & 587.90 & 229.46 & 0.203 \\
HF [ms $\left.{ }^{2}\right]$ & 696.50 & 426.24 & 630.40 & 359.11 & 0.22 \\
LF/HF & 1.13 & 0.28 & 1.02 & 0.126 \\
\hline
\end{tabular}

Table 4. Comparison of mean indices of temporal and spectral HRV analysis determined at rest in the experimental group (swimmers during the completion phase of a training cycle, $n=10)$ and in the controls $(n=30)$

\begin{tabular}{cccccc}
\hline \multirow{2}{*}{ Index } & \multicolumn{2}{c}{$\begin{array}{c}\text { Experimental group during the com- } \\
\text { petition phase }\end{array}$} & \multicolumn{2}{c}{ Control group } & $P$ \\
\cline { 2 - 4 } & mean & SD & mean & SD \\
\hline mRR & 915.70 & 91.38 & 806.00 & 84.44 & 0.001 \\
SDNN [ms] & 128.00 & 45.01 & 93.03 & 28.95 & 0.020 \\
pNN50 [\%] & 28.91 & 17.22 & 22.18 & 16.04 & 0.235 \\
rMSSD [ms] & 72.70 & 51.35 & 59.83 & 31.53 & 0.540 \\
TP [ms $\left.{ }^{2}\right]$ & 224.70 & 845.12 & 1790.00 & 639.85 & 0.143 \\
LF [ms $\left.{ }^{2}\right]$ & 699.50 & 233.95 & 487.35 & 169.20 & 0.009 \\
HF [ms $\left.{ }^{2}\right]$ & 696.50 & 426.24 & 604.70 & 320.26 & 0.520 \\
LF/HF & 1.13 & 0.28 & 0.91 & 0.28 & 0.039 \\
\hline
\end{tabular}

Influence of a single moderate physical exercise on the activity of ANS during the transitory phase of training cycle

A single bout of moderate training load applied during the transitory phase was reflected by a decrease in mean post-exercise values of $\mathrm{mRR}, \mathrm{SDNN}$, and
pNN50 as compared to respective pre-exercise levels. These differences proved statistically significant suggesting a potential exercise-related decrease in the activity of the vagal nerve. In contrast, the decrease in HRV indices observed in spectral analysis proved insignificant (Table 2). 


\section{Influence of a single intense physical exercise on the activity of ANS in swimmers}

A decrease in most HRV indices observed in response to a single intense training load was similar as that documented during the transitory phase of a training cycle. Only a decrease in $\mathrm{mRR}$ and pNN50 proved significant (Table 3 ). The decrease in $\mathrm{mRR}$ corresponded to an increase in HR, from $65.5 \pm 6.5$ to $72.5 \pm 7.1$ beats per minute.

\section{Influence of physical exercise on the activity of ANS in swimmers and in the controls}

The values of indices determined during temporal analysis (Table 4) suggest that, compared to the controls, our swimmers were characterized by significantly higher values of $\mathrm{mRR}$, SDNN, pNN50, and rMSSD. Also the values of spectral indices, TP, HF, LF, and LF/ $\mathrm{HF}$, were higher in the trained individuals (swimmers) as compared to the untrained ones (controls). The intergroup differences in such parameters as $\mathrm{mRR}$, SDNN, LF, and LF/HF proved the most significant, suggesting that the parasympathetic activity in swimmers is higher than in non-sportspersons.

\section{Discussion}

The fact that four months of exercise were not reflected by a persistent switch of vegetative balance into the sympathetic predominance is an important and novel finding of our study. This finding is consistent with data obtained from coaches who claimed that their athletes resumed their optimal form, as suggested by the lack of overtraining signs during the long period of intensive training preparing them to participation in competitions. These findings are also similar to results achieved by other authors on theirs similar researches [4]. On the basis of our findings it can be concluded that moderate physical exercise does not constitute a significant stimulus leading to changes in the vegetative activity of professional athletes. In particular, this refers to the athletes who have completed the so-called preparatory period; generally, such sportspersons should be well prepared to the load associated with the competition period of the yearly training cycle.

We noted only changes of ANS balance (decrease of SDNN and pNN50 parameters - indicators of vagal activity from time domain analysis of HRV) direct after single training period during the preparatory and competition phase of the training cycle. Our findings confirmed Schaal et al [14] which investigated the parasympathetic reactivation and metabolic parameters after exercise load in elite synchronized swimming. They found the significant decreases in HRV indices after exercise with return it to pre-exercise levels during recovery period.

Our findings suggest that the long-term application of training load in the analyzed group of swimmers preparing for competition was not associated with increase in the sympathetic tone (sympathotony), both potentially health-threatening and affecting negatively sports results. Sartor et al [8] who studied elite athletes suggested that RR difference or SD1 difference from HRV analysis could be useful in monitoring training load.

Previous data suggests that excessive physical exercise can be reflected by reversal in the sympatheticparasympathetic balance in favor of the sympathetic system $[13,16]$. Interesting data on the activity of ANS in athletes was published by Iellamo [13], who studied a group of rowers preparing to the World Championships. He observed that the load corresponding to $75 \%$ of the maximal load was reflected by a decrease in the values of LF and LF/HF indices and the increase in HF, considered a marker of increased parasympathetic tone. However, increasing the load to $100 \%$ was associated with the constant switch of the autonomic function from parasympathetic to sympathetic predominance, manifested by an increase in LF and LF/ HF along with a decrease in HF.

On the basis of the aforementioned findings one could expect similar functional changes of ANS in our swimmers. However, although we observed a slight increase in LF/HF index when the competition phase was compared to the preparatory one, this difference did not prove statistically significant. Probably, this absence of significant differences and the lack of conversion of the ANS activity towards the sympathetic predominance resulted from the fact that the training regimen of the analyzed group of swimmers was less intense than in the case of rowers reported by Iellamo [13]. Therefore, the training stimulation applied to our swimmers was probably too weak to induce the proper expected physiological response of their organisms. This might be the reason why their achievements during the Senior and Youth Polish National Championships, i.e. the main event of the season, were poorer than expected.

It should be mentioned that an increasing attention is paid to the individualization of load used in the training of athletes who prepare for competition. Analyzing changes in the function of ANS in our participants one should consider that various individuals respond differently to the same physical stimulus. Frequently, the unambiguous interpretation of the clinical importance of such changes can be difficult. Nevertheless, it cannot be excluded that the comprehensive analysis of the vegetative function of individual athletes will allow for defining various types of ANS responses to physical exercise [17]. This would enable more precise monitoring of athlete's organism, and thus the precise steering of his/her training process and achieving expected sports results. 


\section{Conclusions}

No significant changes in various vegetative time and spectral analysis HRV indices were documented in response to the long-term training cycle with progressive exercise, preparing athletes for competition. However, in response to a single bout of moderate and intense exercise we observed small statistically significant changes in time domain indicators (SDNN, pNN50). However these changes were random so in this case can't be said that such heavy load training is dangerous and is associated with symptoms of overtraining.

\section{Declaration of interest}

The authors report no conflicts of interest.

\section{References}

1. Lutosławska G, Hubner-Woźniak E. Zespół przetrenowania - objawy, mechanizmy i metody wykrywania. Med Sport 2000, 103: 9-14.

2. Raczak G, Daniłowicz-Szymanowicz L, Kobuszewska-Chwirot $\mathrm{M}$, et al. Evaluation of long-term influence of endurance sport on autonomic nervous system activity. Folia Cardiol 2005, 12 (7): 504-9.

3. Vinet A, Beck L, Nottin S, et al. Effect of intensive training on heart rate variability in prepubertal swimmer. Eur J Clinic Inv 2005, 35: 610-4.

4. Daniłowicz-Szymanowicz L, Figura-Chmielewska M, Raczak A, et al. Ocena wpływu długotrwałego intensywnego wysiłku fizycznego na czynność autonomicznego układu nerwowego w grupie sportowców przygotowujących się do startu w zawodach. Polski Merkuriusz Lekarski 2011, XXX: 175: 19-25.

5. Raczak G, Ratkowski W, Szwoch M, et al.The influence of mild exercise on autonomic nervous system function in healthy young men. Folia Cardiol 2003, 10 (2): 195-201.

6. Gawroński W, Szyguła Z. Zmęczenie, przetrenowanie i sposoby intensyfikacji wypoczynku. In: Jegier A, Nazar K, Dziak A. Medycyna Sportowa. Warszawa: Polskie Towarzystwo Medycyny Sportowej, 2005: 465-81.

7. Foster C, Lehman M. The overtraining syndrome. Med Sport 2002, 6 (4): 229-37.
8. Sartor F, Vailati E, Valsecchi V et al. Heart rate variability reflects training load and psychophysiological status in young elite gymnasts. J Strength Cond Res 2013, Jan 28. [Epub ahead of print]

9. Hellard P, Guimaraes F, Avalos M et al. Modeling the association between $\mathrm{HR}$ variability and illness in elite swimmers. Med Sci Sports Exerc 2011, 43(6), 1063-70.

10. Bompa TO, Carrera MC. Periodization training for sports. Champaign, IL: Human Kinetics, 2013.

11. Rakowski M [Ed.]. Modern swimming training. CRS Rafa, Rumia, 2008.

12. Costas K, Terry P. Inside Sport Psychology. Champaign, IL: Human Kinetics, 2011.

13. Iellamo F, Legramante J, Pigozzi F, et al. Conversion from vagal to sympathetic predominance with strenuous training in high-performance world class athletes. Circulation 2002, 105: 2719-24.

14. Schaal K, Le Meur Y, Bieuzen F, et al. Effect of recovery mode on postexercise vagal reactivation in elite synchronized swimmers. Appl Physiol Nutr Metab 2013, 38(2), 126-33

15. Pichot V, Busso T, Roche F, et al. Autonomic adaptations to intensive and overload training periods: a laboratory study. Med Sci Sports Exerc 2002; 34(10): 1660-6.

16. Melanson E. Resting heart rate variability in men varying in habitual physical activity. Med Sci Sports Exerc 2000, 32: 1894-901.

17. Task Force of the European Society of Cardiology and The North American Society of Pacing and Electrophysiology: Heart rate variability. Standards of measurement, physiological interpretation and clinical use. Circulation 1996, 93: 1043 - 65.

Accepted: September 10, 2013

Published: September 27, 2013

Address for correspondence:

Klaudia Palak, MSc

Study Center for Physical Education and Sport,

AGH University of Science and Technology in Cracow

ul. Piastowska 26a

30-070 Cracow, POLAND

Mobile +48600951938

E-mail: klaudiapalak@o2.pl

Agata Furgała: a.furgala@uj.edu.pl

Piotr Biel: pbiel@agh.edu.pl

Zbigniew Szyguła: zbigniew.szygula@awf.krakow.pl

Piotr J. Thor: mfthor@cyf-kr.edu.pl

\begin{tabular}{llll}
\hline Authors' contribution & B - Data Collection & D - Data Interpretation & F- Literature Search \\
A - Study Design & C - Statistical Analysis & E - Manuscript Preparation & G - Funds Collection
\end{tabular}

